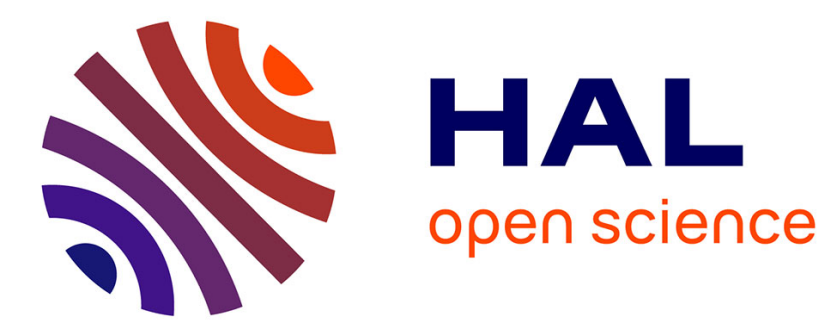

\title{
Voltage Regulation in Distribution Grid Using PV Smart Inverters
}

Remy Rigo-Mariani, Tu A Nguyen, Miguel A Ortega-Vazquez, Daniel S Kirschen

\section{- To cite this version:}

Remy Rigo-Mariani, Tu A Nguyen, Miguel A Ortega-Vazquez, Daniel S Kirschen. Voltage Regulation in Distribution Grid Using PV Smart Inverters. 2018 IEEE Power \& Energy Society General Meeting (PESGM), Aug 2018, Portland, France. pp.1-5, 10.1109/PESGM.2018.8586453 . hal-03520011

\section{HAL Id: hal-03520011 \\ https://hal.science/hal-03520011}

Submitted on 10 Jan 2022

HAL is a multi-disciplinary open access archive for the deposit and dissemination of scientific research documents, whether they are published or not. The documents may come from teaching and research institutions in France or abroad, or from public or private research centers.
L'archive ouverte pluridisciplinaire HAL, est destinée au dépôt et à la diffusion de documents scientifiques de niveau recherche, publiés ou non, émanant des établissements d'enseignement et de recherche français ou étrangers, des laboratoires publics ou privés. 


\title{
Voltage Regulation in Distribution Grid Using PV Smart Inverters
}

\author{
Tu A. Nguyen*, Rémy Rigo-Mariani ${ }^{\dagger}$, Miguel A. Ortega-Vazquez ${ }^{\ddagger}$, Daniel S. Kirschen ${ }^{\S}$ \\ * Sandia National Laboratories, Albuquerque, NM \\ $\dagger$ Cambridge Centre for Advanced Research and Education in Singapore (CARES), Singapore \\ $\ddagger$ Electric Power Research Institute (EPRI), Palo Alto, CA \\ $\S$ University of Washington, Seattle, WA \\ Email: tunguy@sandia.gov, remyrm@ntu.edu.sg, m.ortega-vazquez@ieee.org, kirschen@uw.edu.
}

\begin{abstract}
The PV penetration in power grid has been growing rapidly during the last decade. While PV systems help provide clean and cheap energy to the customers, they also create technical issues in the distribution network. One of the most common problems is the voltage deviation from the acceptable range defined by the current standards. This paper proposes two control algorithms for voltage regulation through reactive power control of multiple PV smart inverters on a single feeder. A case study of a feeder on the University of Washington (UW) campus is conducted to demonstrate the algorithms feasibility.

Index Terms-Renewable energy, distribution systems, smart inverters, voltage regulation, reactive power control, volt-var control.
\end{abstract}

\section{INTRODUCTION}

Over the last decade, the worldwide PV generation has been increasing exponentially due to the fall in costs, the increased customer awareness and supporting governments' policies. According to the IEA [1], at the end of 2015 the globally cumulative PV capacity reached $228 \mathrm{GW}$. It is also predicted that the installed PV capacity will continue to grow over $20 \%$ every year in the next 5 year. This rapid growth of PV generation helps the nations fulfill their energy needs without increasing fossil fuel consumption which largely contributes to greenhouse gaseous emissions.

Although the integration of PV is promoted worldwide, the current distribution systems were not designed to incorporate this type of generation [2]. Consequently, technical problems may occur as the level of PV penetration increases. One of the most common problems is voltage deviation from the acceptable thresholds defined by the current standards. For example, high PV generation during a low demand period might create over-voltages while a sudden drop in PV generation during a peak demand period might create under-voltages [3]. Furthermore, the high intermittency and the reverse power flow from PV generation can interfere with the operations of the existing voltage regulation devices, such as on-load tap changers (OLTC), step voltage regulators (SVR), fixed capacitors (FC) and switchable capacitors (SC) [4].

In order to mitigate the aforementioned issues, the following solutions can be applied in practice:

- Install network protectors at substations to prevent reverse power flow to the networks.
- Deploy energy storage systems (ESS) to reduce intermittency and reverse power flow from PV generation.

- Utilize the reactive power capability of PV inverters for voltage regulation.

The first solution is often used by the utilities. Although this practice can prevent most of the above issues, it increases PV generation curtailment, thereby reducing the benefits of PV installations [5]. The second solution has gained more attention recently as the cost of energy storage decreases. This method requires to optimally control the ESSs such that the total economic benefit is maximized $[6,7]$.

This paper focuses on voltage regulation using PV smart inverters. This practice is rather new in the United States because only recently did the interconnection standards for distributed generation systems such as IEEE 1547 [8] allow $\mathrm{PV}$ inverters to inject/absorb reactive power. The advantage of an inverter in comparison with traditional voltage regulators (OLTC, SVR, SC) is that its reactive power output can vary much faster [9]. To fully take advantage of its reactive power capability, a PV inverter must be properly controlled so that it can efficiently regulate the voltage while delivering maximum active power [10]. Reactive power control of PV inverters has been studied in the literature. The existing methods (as reviewed in Section II) often neglect the power factor limits of the PV inverters. Furthermore, most of them only study the impact of a single PV inverter on a feeder.

In this paper, we propose two control algorithms for voltage regulation through reactive power control of the PV smart inverters. Power factor adjustments and voltage measurements are used to maintain the voltages within a predefined range. Multiple PV systems on a single feeder are also considered in these algorithms. A case study is conducted to demonstrate the algorithms feasibility. The rest of this paper is organized as follows: section II presents the reactive power capability of PV smart inverters and the existing control methods; section III introduces the two new methods for voltage regulation support using PV smart inverters; section IV describes a case study considering a feeder on the UW distribution network; section $\mathrm{V}$ summarizes the paper with concluding remarks. 


\section{REACTIVE POWER CAPABILITY OF PV SMART INVERTERS AND EXISTING CONTROL METHODS}

\section{A. Reactive power capability of $P V$ smart inverters}

In order to enable the reactive power capability of PV inverters, it is required that the inverter power rating is oversized. In other words, the apparent power of the inverter $\left(S_{P V}\right)$ must be greater than the real power output of the $\mathrm{PV}$ arrays $\left(P_{P V}\right)$ to use the excess capability for providing reactive power $\left(Q_{P V}\right)$. It is important to note that the storage capacitor inside the inverter must also be suitably oversized to handle the voltage ripple while injecting/absorbing reactive power. Therefore, the reactive power capabilities of the PV smart inverters are often limited when small capacitors are installed to reduce the cost and the dimensions of the inverter. This is reflected in the power factors of the inverters. For example, the power factor of an inverter can be as low as 0.7. This means the inverter can only provide as much reactive power as its real power, and cannot provide reactive power at night when there is no PV generation.

The relationship between different output powers of a smart inverter is illustrated in Figure 1 where $\theta$ is the power factor angle. $p f$ is the power factor limited by $p f^{+}$(leading) and $p f^{-}$(lagging). The power factor can be adjusted to change the reactive power output. The blue (red) arrow in the figure shows the direction toward an increase (decrease) when more (less) reactive power is injected into the grid. For example, by changing the power factor from $\theta_{1}$ position to $\theta_{2}$ position, the reactive power injection increases by $\Delta Q_{P V}$ thereby increasing the voltage by $\Delta V>0$. Correspondingly, the active power output decreases by $\Delta P_{P V}$.

The reactive power limits of the smart inverters are functions of real PV power, and calculated as follows:

$$
\begin{aligned}
& Q_{P V}^{\max }=\min \left\{P_{P V} \tan \left(\theta_{\text {max }}\right), S_{r} \sin \left(\theta_{\text {max }}\right)\right\} \text { (Positive) } \\
& Q_{P V}^{\text {min }}=\max \left\{P_{P V} \tan \left(\theta_{\text {min }}\right), S_{r} \sin \left(\theta_{\text {min }}\right)\right\} \text { (Negative) }
\end{aligned}
$$

\section{B. Existing methods for reactive power control of PV inverters}

Several reactive power control of PV inverters have been described in the literature. Many of them are droop-based controls which operate as follows:

1) Constant $Q$ [11]: in this control method, the reactive power output is fixed. The power factor limit and the apparent power limit must be met, therefore the reactive power output must be selected between $Q_{P V}^{\max }$ and $Q_{P V}^{\min }$.

2) Constant pf [11-13]: in this control method, the power factor is kept constant. Thus, the reactive power output is proportional to the real $\mathrm{PV}$ power:

$$
Q_{P V}=P_{P V} \tan (\theta) \text { with } P_{P V} \leq S_{r} \cos (\theta)
$$

As seen in Eq. (3) the real power output is bounded. Therefore when PV generation is high, it can be curtailed to maintain constant power factor. This method can be applied when the voltage violations are always in one direction (i.e., either undervoltage or overvoltage). For example, in a network with

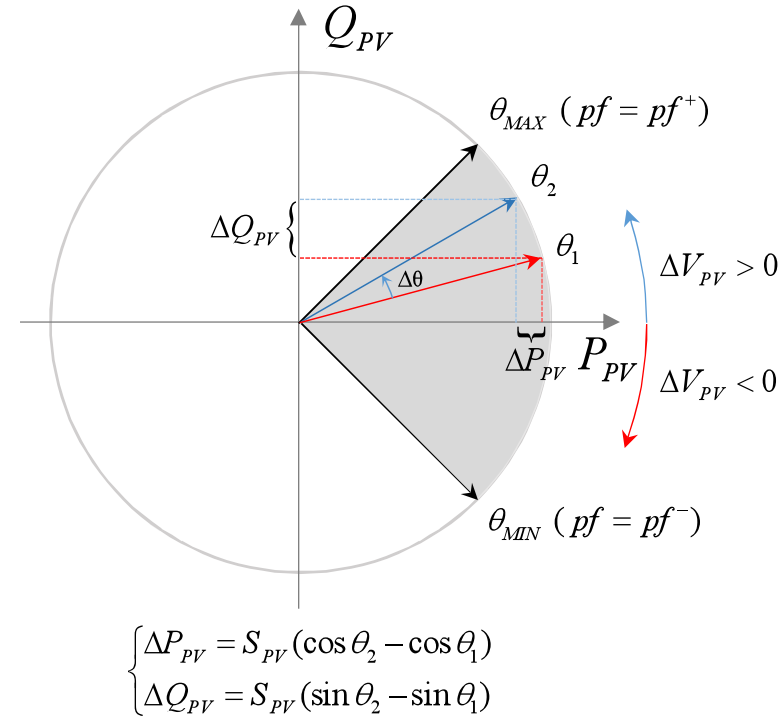

Fig. 1. Smart inverters real and reactive power

high PV penetration, the voltage is often higher than the acceptable limit.

3) pf-Watt $(p f(P))[11,13-16]$ : in some cases, the real PV power can be consumed locally and there is no need to control the reactive power. In this case, the previous control methods fail to drive the reactive power output to zero. In the $p f(P)$ method, the power factor of the inverter is predefined as a piecewise linear function of real power (Eq. (4)). Therefore, it has the flexibility to decide when to provide reactive power to the grid.

$$
p f(P)= \begin{cases}p f_{1} & \text { if } P<P_{1} \\ \frac{p f_{1}-p f_{2}}{P_{1}-P_{2}}\left(P-P_{1}\right) & \text { if } P_{1} \leq P \leq P_{2} \\ p f_{2} & \text { otherwise }\end{cases}
$$

4) Volt-Var $(Q(V))[11,13-15,17-19]$ : in the above methods, the voltage is regulated indirectly as the reactive power control only takes PV real power as input. This might lead to high control error and in some cases might move the voltage in the wrong direction. In the $Q(V)$ method, the reactive power output is controlled based on the voltage. The voltage thresholds are often selected based on the voltages at different locations along the feeder (Eq. (5).

$$
Q(V)= \begin{cases}Q^{\max } & \text { if } V<V_{1} \\ \frac{Q^{\max }}{V_{1}-V_{2}}\left(V-V_{1}\right)+Q^{\max } & \text { if } V_{1} \leq V \leq V_{2} \\ 0 & \text { if } V_{2} \leq V \leq V_{3} \\ \frac{Q^{\max }}{V_{3}-V_{4}}\left(V+V_{3}\right) & \text { if } V_{3} \leq V \leq V_{4} \\ -Q^{\text {max }} & \text { otherwise }\end{cases}
$$

In all of the above methods, the voltage control is open loop and based on a predefined set of rules. The advantage of these 


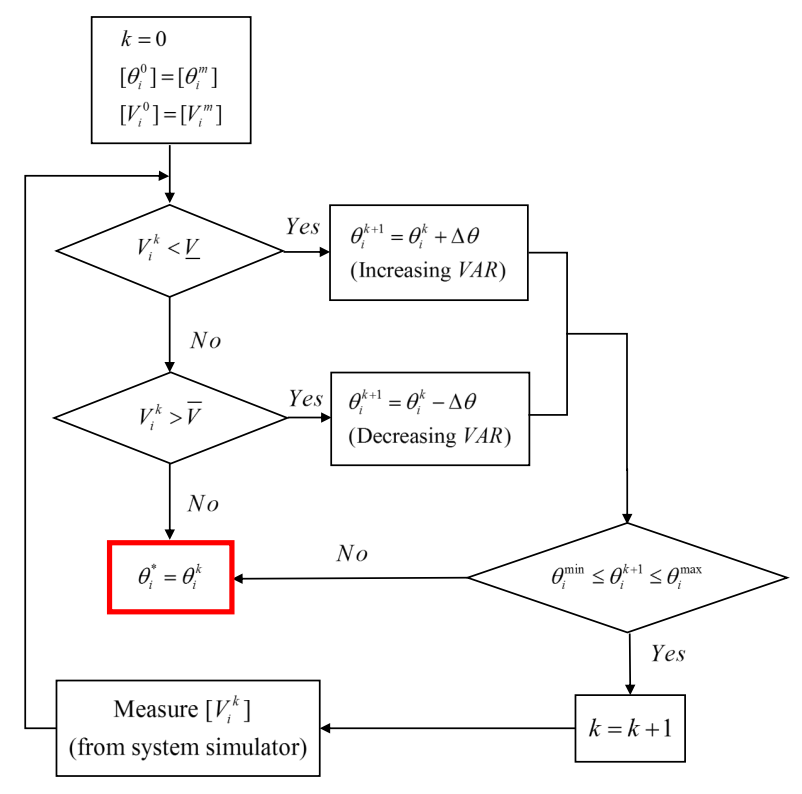

Fig. 2. Greedy control algorithm

methods is their simple implementation. Nevertheless, these controls might need tuning frequently as the PV generation profiles change seasonally and annually. Different methods to optimally choose the droop settings for method 3 and method 4 have been studied in [11, 13, 16, 19]. Beside the droop-based methods, other methods have also been studied. In [2, 20, 21], distributed optimal controls of PV inverters reactive power was performed to regulate the voltage while minimizing the ohmic loses of the radial distribution systems. A least square method was used in [22] to find the optimal references for PV inverters reactive control which minimize the differences between real and targeted voltages. A method which combines centralized and distributed control for PV inverters in unbalanced distribution system is presented in [23]. A stochastic reactive power management which considered uncertainties and delays in the system states is proposed in [24].

\section{Proposed Methods FOR VOlTage REgulation SUPPORT USING PV SMART INVERTERS}

\section{A. Greedy method}

Fig. 2 shows the greedy control algorithm in which voltage measurements are acquired periodically (typically every 5 minutes). The voltage is compared to the limits and the power factor angle is adjusted accordingly to increase or decrease the amount of reactive power injected to the grid. Before sending the power factor reference to the inverters control, the voltage is estimated by system simulator to ensure the voltage after the power factor adjustment does not violate the limits. The system simulator can be a power flow solver or a sophisticated real time digital simulator. This algorithm only takes the local

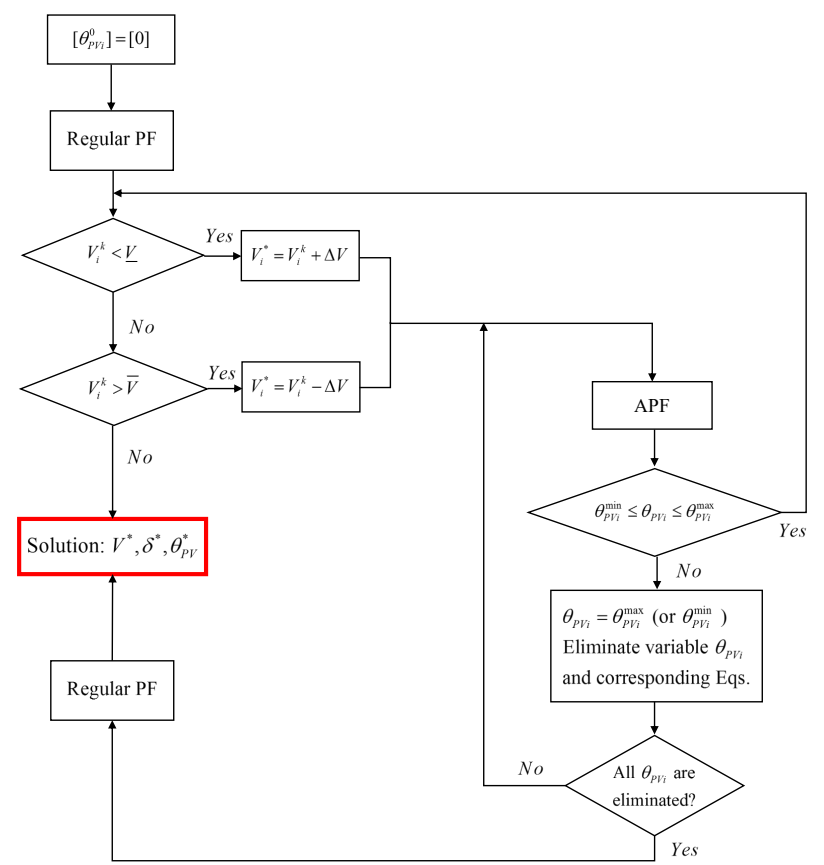

Fig. 3. APF-based control algorithm

voltage as the input, therefore it can be used locally without complicated communication system. The drawback of this control method occurs when the voltages at different inverter nodes are strongly dependent such as in a rural network with long feeders. Therefore, this control method should only be applied in networks where the feeders are short.

\section{B. Augmented-power-flow (APF) method}

In this method, the power factor angles of the inverters are introduced into the power flow equations as unknowns. Therefore, a new set of equations are also introduced.

$$
\left\{\begin{aligned}
f_{i}^{P} & =P_{i}(V, \delta)-S_{i}^{P V} \cos \left(\theta_{i}^{P V}\right)+P_{i}^{D}=0 \\
f_{i}^{Q} & =Q_{i}(V, \delta)-S_{i}^{P V} \sin \left(\theta_{i}^{P V}\right)+Q_{i}^{D}=0 \\
f_{i}^{V} & =V_{i}-V_{i}^{*}=0
\end{aligned}\right.
$$

In Eq. (6), $P_{i}(V, \delta)$ and $Q_{i}(V, \delta)$ (as functions of voltages and voltage angles) are real power and reactive power at bus $i . P_{i}^{D}$ and $Q_{i}^{D}$ are real and reactive load at bus $i . \theta_{i}^{P V}$ is the new variable that represents the PV inverter's power factor angle at bus $i . f_{i}^{V}$ is the new set of equations in which $V_{i}^{*}$ is the target voltage at bus $i$ where PV is installed. This system of equations can be solved using the Newton-Raphson method:

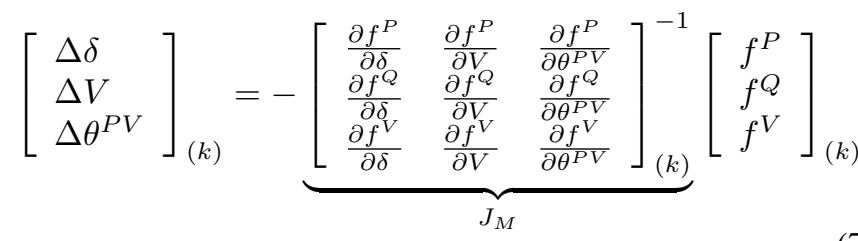




$$
\left[\begin{array}{l}
\delta \\
V \\
\theta^{P V}
\end{array}\right]_{(k+1)}=\left[\begin{array}{l}
\delta \\
V \\
\theta^{P V}
\end{array}\right]_{(k)}+\left[\begin{array}{l}
\Delta \delta \\
\Delta V \\
\Delta \theta^{P V}
\end{array}\right]_{(k)}
$$

where $J_{M}$ is the augmented Jacobian matrix and $\frac{\partial f^{P}}{\partial \theta^{P V}}, \frac{\partial f^{Q}}{\partial \theta^{P V}}$, $\frac{\partial f^{V}}{\partial \delta}, \frac{\partial f^{V}}{\partial V}, \frac{\partial f^{V}}{\partial \theta^{P V}}$ are the added elements due to the new equations and variables.

The proposed control algorithm based on APF is shown in Fig. 3 where the load and system states are input at each time period. The inverters start at unity power factor. Voltages at the initial step can be measured or calculated using a regular power flow solver. The target voltages are adjusted if any of the inverter voltages are out of range and the APF is run to find the inverters power factor angles. If the power factor at an inverter node reaches its limit, this power factor angle is eliminated from the APF equations. The process is iterated until all voltages are within the acceptable range or all power factors reach their limits.

This method requires a communication system to collect measurements and send command signals to the inverters. Load, weather, and system information are sent to the control center where the control references are calculated and the command signals are sent to all devices. The latency of the communication might impact the optimal operation of the system. However, it is not considered in this paper.

\section{A CASE STUDY}

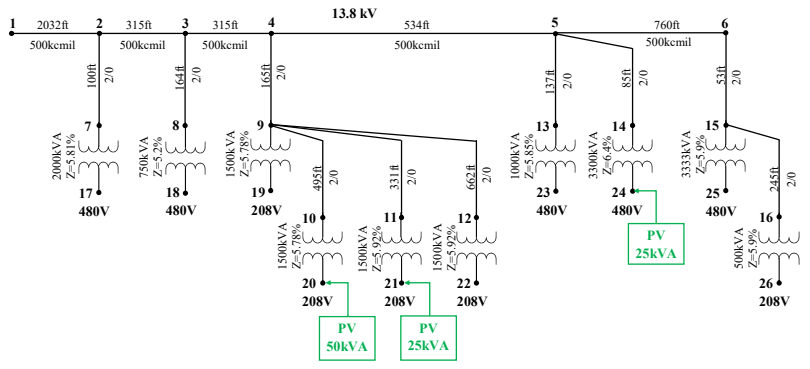

Fig. 4. Feeder data

In this section, we investigate a feeder on the University of Washington distribution network where three PV systems are installed (Fig. 4). The feeder is modeled in Gridlab-D and Matlab. The APF algorithm is implemented in Matlab with Matpower $6.01 \mathrm{~b}$. To better evaluate the feasibility of the proposed method, the capacities of the three PV systems are assumed to be five times larger than their actual values. Each PV system is equipped with smart inverters with power factor adjustable between 0.7 leading and 0.7 lagging. Load and weather data are imported from historical data of May-01-2016. The acceptable voltage range is assume to be $[0.99,1.01]$.

The results shown in Fig. 5 and Fig. 6 are for bus 20 . Similar results for the other PV buses were also achieved.
As observed in the figures, the control methods are effective only when PV generation is high. In this case the power factor limits of the inverters only allow to provide as much reactive power as real power. Therefore, when there is no or low PV generation the voltage regulation support from the inverters is not effective. It is also observed that the real power output is reduced significantly during peak sun in order to inject reactive power to the grid. The reactive power output from the APF method is just enough to keep the voltage inside the acceptable range when possible. This is to maximize the PV real power output. On the other hand, the Greedy method utilizes the reactive power capability of the inverters. When the PV generation is low the solutions of the two methods are the same because the power factor angle reaches it limits.
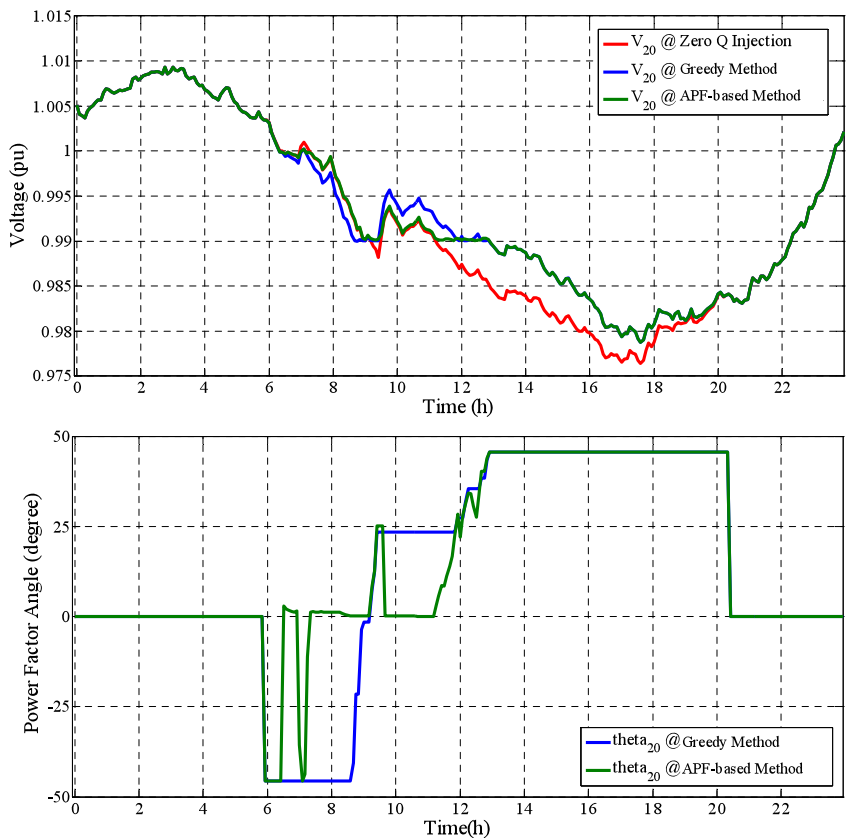

Fig. 5. Voltage and power factor angle at bus 20

\section{Conclusions}

In this paper, current practices for voltage regulation have been described. The reactive power capability of PV smart inverters and existing control methods have been reviewed. In this work, we proposed two algorithms for voltage regulation support using PV smart inverters. The APF method maintains the voltage with minimal reactive power to maximize the PV real power output. On the other hand, the Greedy method utilizes the reactive power capability of the inverters. A case study is conducted to investigate a feeder on the UW distribution network. The results demonstrate the feasibility of the proposed algorithms. Future work in this area would involve the integration of energy storage systems to utilize the reactive power capability of $\mathrm{PV}$ inverters.

\section{ACKNOWLEDGMENTS}

The work presented in this paper was carried out as part of the Clean Energy and Transactive Campus project in 

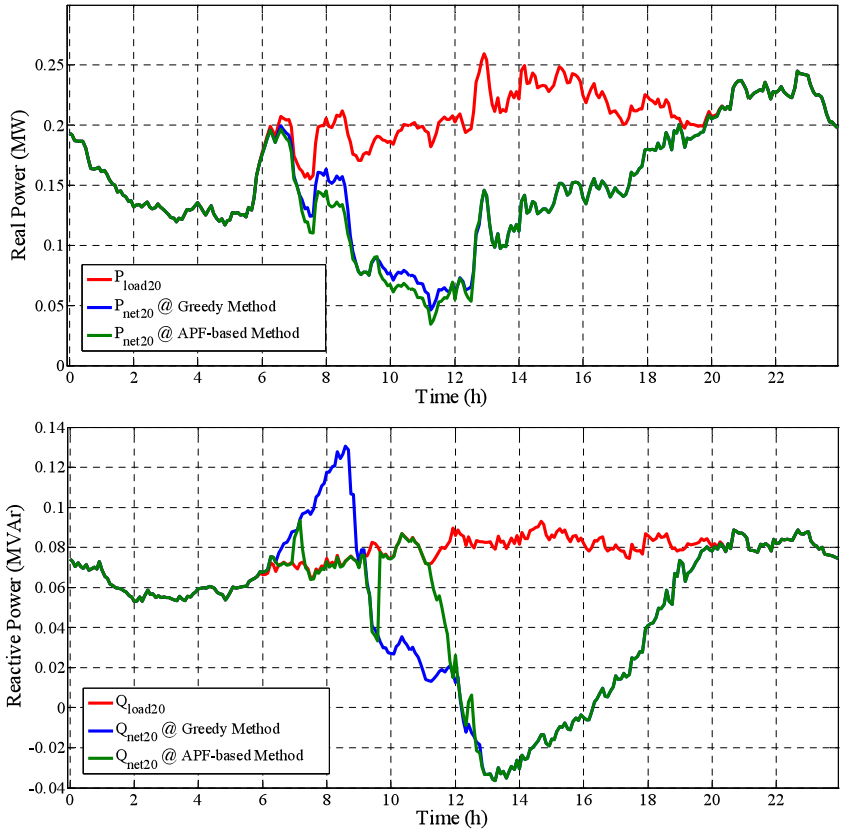

Fig. 6. Real and reactive power at bus 20

partnership with the Pacific Northwest National Laboratory (PNNL) and Washington State University (WSU). The authors would like to thank the U.S. Department of Energy and the Washington State Department of Commerce for funding this project.

\section{REFERENCES}

[1] "2016 trends in photovoltaic applications," International Energy Agency, Tech. Rep., 2016.

[2] K. Tanaka, "Decentralized voltage control in distribution systems by distributed generators," in 2009 IEEE International Symposium on Industrial Electronics, July 2009, pp. 554-559.

[3] R. Tonkoski, D. Turcotte, and T. H. M. EL-Fouly, "Impact of high pv penetration on voltage profiles in residential neighborhoods," IEEE Transactions on Sustainable Energy, vol. 3, no. 3, pp. 518-527, July 2012.

[4] H. Ravindra, M. O. Faruque, K. Schoder, M. Steurer, P. Mclaren, and R. Meeker, "Dynamic interactions between distribution network voltage regulators for large and distributed pv plants," in 2012 IEEE PES Transmission and Distribution Conference and Exposition (T\&D), May 2012, pp. 1-8.

[5] R. A. Walling, R. Saint, R. C. Dugan, J. Burke, and L. A. Kojovic, "Summary of distributed resources impact on power delivery systems," IEEE Transactions on Power Delivery, vol. 23, no. 3, pp. 1636-1644, July 2008.

[6] J. Eyer and G. Corey, "Energy storage for the electricity grid: Benefits and market potential assessment guide," Sandia National Laboratories, Albuquerque, NM, SAND2010-0815, Tech. Rep., Feb 2010.

[7] R. H. Byrne, T. A. Nguyen, D. A. Copp, B. R. Chalamala, and I. Gyuk, "Energy management and optimization methods for grid energy storage systems," IEEE Access, vol. PP, no. 99, pp. $1-1,2017$.

[8] T. S. Basso and R. DeBlasio, "Ieee 1547 series of standards: interconnection issues," IEEE Transactions on Power Electronics, vol. 19, no. 5, pp. 1159-1162, Sept 2004.

[9] Y. Liu, J. Bebic, B. Kroposki, J. de Bedout, and W. Ren, "Distribution system voltage performance analysis for high- penetration pv," in 2008 IEEE Energy 2030 Conference, Nov 2008, pp. 1-8.

[10] C. Whitaker, J. Newmiller, M. Ropp, and B. Norris, "Distributed photovoltaic systems design and technology requirements," Sandia National Laboratories, Albuquerque, NM, SAND2008-0946 P, Tech. Rep., Feb 2010.

[11] E. Demirok, P. C. Gonzlez, K. H. B. Frederiksen, D. Sera, P. Rodriguez, and R. Teodorescu, "Local reactive power control methods for overvoltage prevention of distributed solar inverters in low-voltage grids," IEEE Journal of Photovoltaics, vol. 1, no. 2, pp. 174-182, Oct 2011.

[12] M. Braun, "Reactive power supply by distributed generators," in 2008 IEEE Power and Energy Society General Meeting - Conversion and Delivery of Electrical Energy in the 21st Century, July 2008, pp. 1-8.

[13] J. W. Smith, W. Sunderman, R. Dugan, and B. Seal, "Smart inverter volt/var control functions for high penetration of pv on distribution systems," in 2011 IEEE/PES Power Systems Conference and Exposition, March 2011, pp. 1-6.

[14] T. Stetz, K. Diwold, M. Kraiczy, D. Geibel, S. Schmidt, and M. Braun, "Techno-economic assessment of voltage control strategies in low voltage grids," IEEE Transactions on Smart Grid, vol. 5, no. 4, pp. 2125-2132, July 2014.

[15] A. R. Malekpour and A. Pahwa, "A dynamic operational scheme for residential pv smart inverters," IEEE Transactions on Smart Grid, vol. 8, no. 5, pp. 2258-2267, Sept 2017.

[16] L. Wang, R. Yan, and T. K. Saha, "Voltage management for large scale pv integration into weak distribution systems," IEEE Transactions on Smart Grid, vol. PP, no. 99, pp. 1-1, 2017.

[17] M. Braun, "Optimal reactive power supply in distribution networks-technological and economic assessment for pvsystems," in 2009 European Photovoltaic Solar Energy Conference, 2009.

[18] M. Velasco, P. Mart, J. Torres-Martnez, J. Miret, and M. Castilla, "On the optimal reactive power control for grid-connected photovoltaic distributed generation systems," in IECON 2015 - 41st Annual Conference of the IEEE Industrial Electronics Society, Nov 2015, pp. 003 755-003 760.

[19] A. O'Connell and A. Keane, "Volt-var curves for photovoltaic inverters in distribution systems," IET Generation, Transmission and Distribution, vol. 11, no. 3, pp. 730-739, 2017.

[20] K. Turitsyn, P. Łulc, S. Backhaus, and M. Chertkov, "Distributed control of reactive power flow in a radial distribution circuit with high photovoltaic penetration," in 2010 IEEE PES General Meeting, July 2010, pp. 1-6.

[21] A. Cagnano, E. D. Tuglie, M. Liserre, and R. A. Mastromauro, "Online optimal reactive power control strategy of pv inverters," IEEE Transactions on Industrial Electronics, vol. 58, no. 10, pp. 4549-4558, Oct 2011.

[22] A. Bonfiglio, M. Brignone, F. Delfino, and R. Procopio, "Optimal control and operation of grid-connected photovoltaic production units for voltage support in medium-voltage networks," IEEE Transactions on Sustainable Energy, vol. 5, no. 1, pp. 254-263, Jan 2014.

[23] S. Weckx, C. Gonzalez, and J. Driesen, "Combined central and local active and reactive power control of pv inverters," IEEE Transactions on Sustainable Energy, vol. 5, no. 3, pp. 776-784, July 2014.

[24] V. Kekatos, G. Wang, A. J. Conejo, and G. B. Giannakis, "Stochastic reactive power management in microgrids with renewables," IEEE Transactions on Power Systems, vol. 30, no. 6, pp. 3386-3395, Nov 2015. 